\title{
THE RENAL REGULATION OF ACID-BASE BALANCE IN MAN. IV. THE NATURE OF THE RENAL COMPENSATIONS IN AMMONIUM CHLORIDE ACIDOSIS ${ }^{1}$
}

\author{
By O. W. SARTORIUS, J. C. ROEMMELT, AND R. F. PITTS WITH THE TECH NICAL \\ ASSISTANCE OF DOROTHY CALHOON AND PHYLLIS MINER
}

\begin{abstract}
(From the Department of Physiology, Syracuse University College of Medicine, Syracuse, New York)
\end{abstract}

(Received for publication December 6, 1948)

The major body buffers, including bicarbonate, plasma and tissue proteins and intracellular organic phosphate complexes, can yield sufficient base within a $\mathrm{pH}$ range compatible with life to neutralize at most $1 \mathrm{~mol}$ of strong acid (1). As an immediate compensation for the invasion of the body by acid, urine of increased hydrogen ion concentration is formed, but since the $\mathrm{pH}$ of the urine is limited to a minimum of 4.4 to $4.7(2,3)$, the quantity of strong acid which can be excreted in free form is negligible. Acid is at first eliminated fully neutralized by base derived from the above mentioned buffers (4-6). According to Gamble the resulting depletion of base stores serves to stimulate the production and excretion of ammonia. Over a period of several days ammonia is substituted in progressively increasing amounts for fixed base in the urine, until eventually nearly all of the acid is eliminated in combination with ammonia (4-7). During recovery from acidosis the excretion of ammonia remains high, and base derived from ingested salt is retained in the body to rebuild buffer stores. Only after these stores are replenished does the excretion of ammonia decrease to normal levels.

The loss of base from both intra- and extracellular compartments during the initial phase of acidosis is accompanied by a compensatory loss of water, leading to cellular and interstitial dehydration and to reduction in circulating plasma volume $(4,6)$. Presumably this latter factor is responsible for the reduction in urea clearance and for the nitrogen retention often observed in severe acidosis (8). However, loss of fluid does not completely compensate for loss of alkali, for the total

1 Aided by grants from the United States Public Health Service and the John and Mary R. Markle Foundation. base concentration of the plasma usually decreases significantly $(4,6,9-11)$.

The acidosis of diabetic ketosis differs from that outlined above chiefly in the greater contribution of titratable acid excretion to total acid elimination $(1,12,13)$. Because of the weakly acidic nature of beta-hydroxybutyric acid appreciable quantities of acid can be eliminated in free form in urine of maximal acidity. In severe diabetic ketosis as much as $0.15 \mathrm{~mol}$ of titratable acid may be excreted per day. However, providing the development of ketosis is slow, some two to three times this quantity of acid is eliminated in combination with ammonia. In rapidly developing ketosis, loss of base and dehydration may reach lethal proportions before the renal production of ammonia increases sufficiently to balance the acid load $(14,15)$. In chronic nephritis the renal capacity to excrete ammonia is reduced (16, 17), and since acid is eliminated for the most part in combination with fixed base, the buffer reserves of alkali suffer progressive depletion (9, 18, 19).

The present study of the response of the normal kidney to an increased load of strong acid was undertaken $(a)$ to relate the rates of excretion of the several ions to their respective plasma concentrations, $(b)$ to determine the nature and extent of the changes in glomerular filtration, renal plasma flow, and ionic reabsorption which underlie altered excretory functions in metabolic acidosis, and (c) to study the time relations of the renal compensations to acidosis. A number of complete though separate studies of acid-base equilibria of plasma and of urinary electrolyte balance have been made in experimental acidosis and in the acidosis of chronic nephritis and diabetes $(9,10,12,13,16-18)$. However, in no study to date have electrolyte balances been re- 
lated to the changes in plasma composition and renal function which ultimately determine their character. The data presented below partially fill this void.

\section{METHODS}

Three types of experimental procedures were applied in this study.

(a) Two healthy adult males were maintained for periods of 15 and 16 days respectively, on a diet constant with respect to salt content and caloric value. Accurate 24-hour urine samples, preserved with toluene, were collected during these periods. Daily blood samples were drawn from a superficial vein after soaking the forearm in water at $47^{\circ} \mathrm{C}$ for $10 \mathrm{~min}$. to render the composition of the venous blood essentially that of arterial blood. The plasma and urine samples of both subjects were analyzed for sodium, chloride, bicarbonate, $\mathrm{pH}$, and phosphate. Hematocrit, urinary specific gravity and urinary content of titratable acid and ammonia were determined daily. The plasma and urine samples of the second subject were in addition analyzed for potassium, calcium, sulphate, and protein, while the urine was further tested for magnesium, organic acid, creatinine, creatine, and amino nitrogen. In the first experiment sodium was analyzed by the method of Butler and Tuthill (20). In the second experiment, sodium and potassium were determined by an internal standard flame photometer ${ }^{2}$ with an accuracy within \pm 2 per cent, as checked against the method of Butler and Tuthill. Magnesium was precipitated as the ammonium phosphate and the latter ion determined colorimetrically (1). Plasma proteins and specific gravity were determined by the copper sulphate method of Phillips et al. (21). Organic acid in urine was determined by electrometric titration of aliquots between limits of $\mathrm{pH} 8.0$ and 2.7 following removal of phosphate with calcium hydroxide. Titrations were corrected for creatinine content of the urine (1). Other methods employed have been described in previous communications $(3,22)$. The first five days of each experiment constituted the control period; the second five days, the period of acidosis; and the remaining five or six days, the recovery period. The first subject ingested $15 \mathrm{gms}$. of ammonium chloride daily in divided doses for the initial two days of acidosis followed by 10 gms. daily for the

2 We are indebted to Dr. Robert L. Bowman of the Department of Medicine of New York University College of Medicine for the design of our flame photometer and for his helpful advice during its construction.

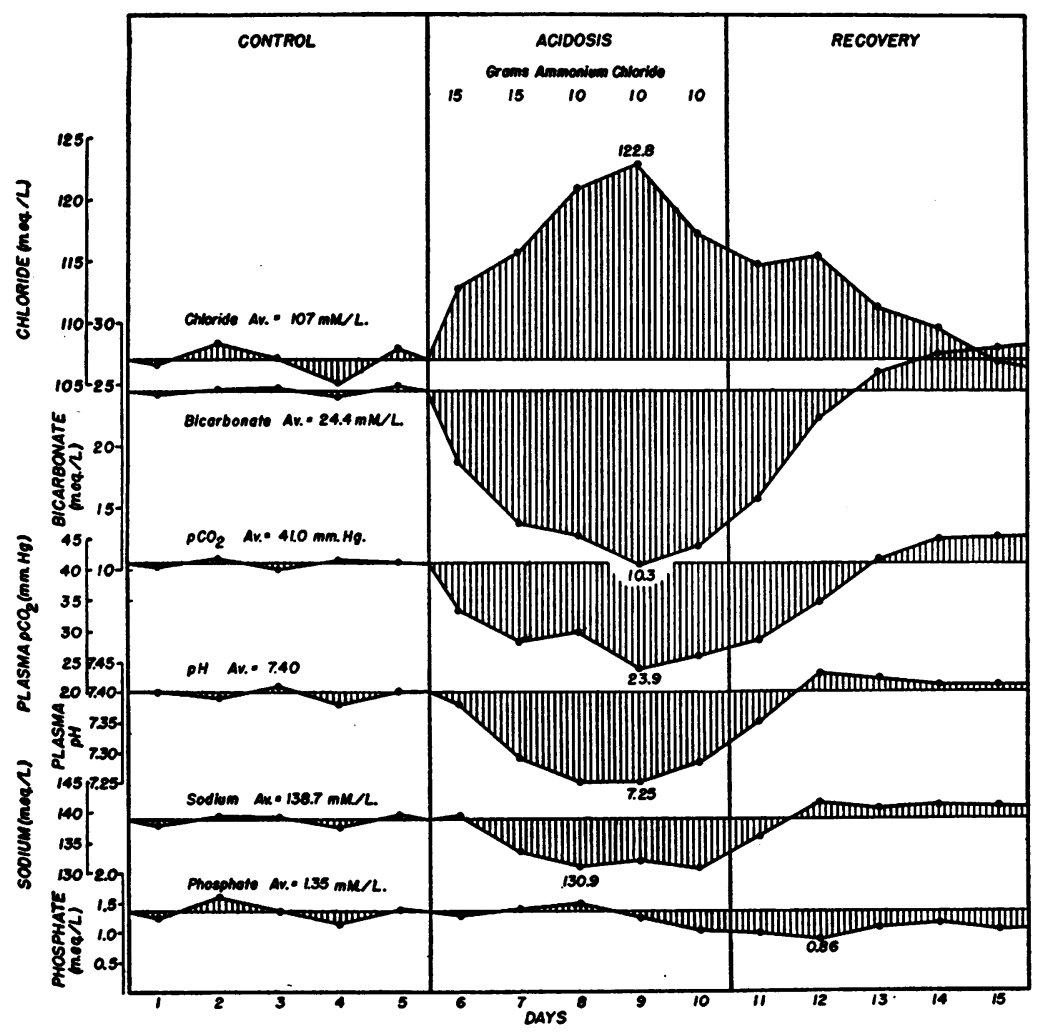

Fig. 1. Changes in the Ionic Composition of the Plasma of Subject P Which Resulted from the Ingestion of 60 Gms. of Ammonium Chloride Over a Five-Day Period 


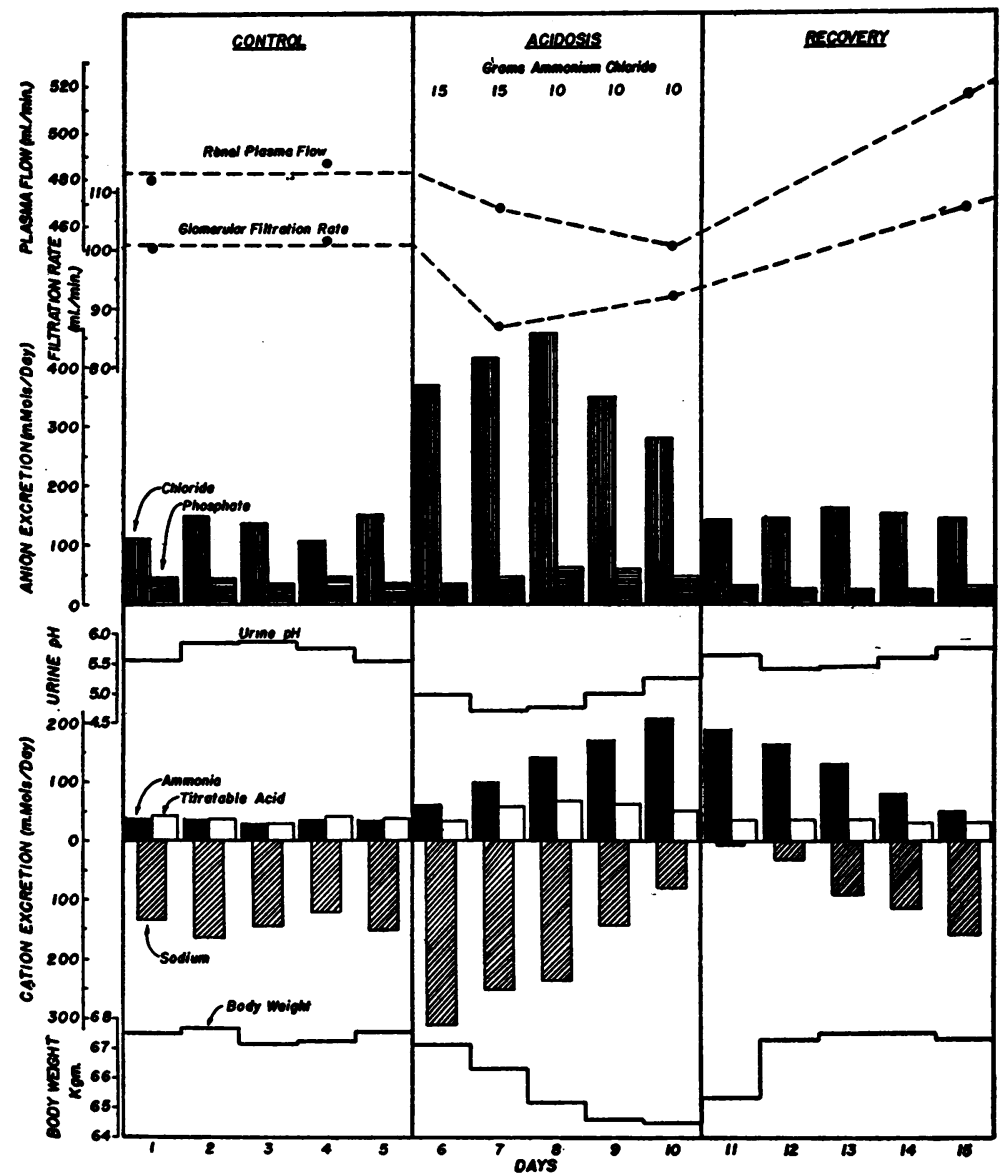

Fig. 2. Changes in the Rates of Excretion of Ions, Renal Plasma Flow, Glomerular Filtration Rate, and Body Weight Which ReSulted from the Ingestion of 60 Gms. of Ammonium Chloride Over a Five-Day Period

remaining three days. The second subject ingested 15 gms. daily throughout the period of acidosis.

(b) Renal clearance experiments were performed at intervals during the control, acidosis, and recovery periods. In the first subject, the rate of glomerular filtration was approximated by mannitol clearances, ${ }^{3}$ performed on the first and fourth days of the control period, the second and fifth days of acidosis and the fifth day of recovery. In the second subject, inulin was used as an exact measure of glomerular filtration rate. Determinations were made on the first and fourth days of each of

3 According to recent studies of Berger et al. (23) the mannitol clearance is significantly lower than the inulin clearance, hence is not an exact measure of glomerular filtration rate. However, the mannitol clearance presumably measures a constant fraction of the glomerular clearance in any one individual. Thus although absolute values for ionic reabsorption calculated from mannitol clearances may be too low, changes in ionic reabsorption are correctly indicated. the three experimental periods. Effective renal plasma flow was determined by the p-amino-hippurate clearance in both subjects.

(c) The acute response of the kidney to acidosis was assessed in one subject in a 12 period experiment, during which a total of $10 \mathrm{gms}$. of ammonium chloride was ingested.

\section{RESULTS}

\section{Acid-base equilibria of plasma and urinary ionic balances in acidosis}

Data on the plasma composition and urinary ionic balance of subject $P$ are summarized in Figures 1 and 2. In Figure 1 are presented the plasma values for chloride, bicarbonate, $\mathrm{pCO}_{2}$, $\mathrm{pH}$, sodium and phosphate. Each variable is referred to a base line established by averaging the five control determinations. Thus the mean 
plasma chloride during the control period was $107 \mathrm{mEq}$ per liter, varying within limits of 105 and $109 \mathrm{mEq}$ per liter. In consequence of ingestion of ammonium chloride, the plasma chloride rose to a peak value of $122.8 \mathrm{mEq}$ per liter on the fourth day of acidosis. In contrast the plasma bicarbonate fell from a mean normal value of $24.4 \mathrm{mEq}$ per liter to $10.3 \mathrm{mEq}$ per liter on that day.

Chloride and bicarbonate varied throughout in reciprocal fashion, the sum of the two remaining roughly constant for the first 11 days of the experiment. However, on the second recovery day, the sum of these two anions increased $6 \mathrm{mEq}$ per liter, for bicarbonate rose more rapidly than chloride fell during this period. The sum of chloride and bicarbonate averaged $7 \mathrm{mEq}$ lower than sodium during the control period and at the end of the recovery period. However, during the period of acidosis, sodium fell 2 to $3 \mathrm{mEq}$ below the sum of these two anions. This finding can be partially explained by the decrease in base binding capacity of the plasma protein due to increased plasma acidity. However, this and other interesting results prompted a more complete ionic study of the plasma and urine in a second subject.

Respiratory compensation is shown by the drop in $\mathrm{pCO}_{2}$ of arterialized venous blood from a normal value of 41.0 to $23.9 \mathrm{~mm}$. $\mathrm{Hg}$ during acidosis; the latter value is indicative of a 70 per cent increase in alveolar ventilation over the normal. The subject was conscious of some increased ventilation at rest and obvious dyspnea on exertion. Presumably this increase in ventilation resulted from the increase in blood acidity from $\mathrm{pH} 7.40$ to 7.25 (24).

The serum sodium concentration dropped significantly on the second day of acidosis and reached a low of $130.9 \mathrm{mEq}$ per liter on the third day, a decrease of $8 \mathrm{mEq}$ per liter. The plasma concentration of phosphate, in contrast, was maintained relatively constant until the fifth day of acidosis.

The concentrations of each of these plasma constituents with the exception of phosphate returned to normal or supra-normal levels within the five-day recovery period. Serum sodium and $\mathrm{pH}$ were restored first, bicarbonate and $\mathrm{pCO}_{2}$ next, and chloride only on the fifth day. There is evident an over-compensation in the return of bicarbonate, $\mathrm{pCO}_{2}, \mathrm{pH}$, and sodium to levels above those existing during the control periods.

In Figure 2 are summarized the rates of excretion of chloride, phosphate, titratable acid, ammonia and sodium, expressed in $\mathrm{mEq}$ per 24 hours; urine $\mathrm{pH}$; body weight; and glomerular filtration rate and renal plasma flow on the five days on which these variables were measured. During the control period the rate of excretion of chloride averaged $130 \mathrm{mEq}$ per-day varying within limits of 107 and $151 \mathrm{mEq}$ per day. In consequence of the ingestion of ammonium chloride and elevation of plasma level, chloride excretion increased to $368 \mathrm{mEq}$ on the first day and to 458 on the third. During these three days there was a net loss of $230 \mathrm{mEq}$ of chloride over and above that ingested in the diet and as ammonium chloride. At a mean concentration of 115 $\mathrm{mEq}$ per liter, this represents a loss of 2 liters of extracellular fluid in the first three days of acidosis. Body weight actually decreased $2.2 \mathrm{Kgm}$. during this interval. Although a rigorous analysis of these data cannot be justified, it is safe to infer that the major loss of weight early in this experiment resulted from loss of extracellular fluid.

The excretion of phosphate increased from an average of $41 \mathrm{mM}$ per day during the control period to a peak of $60 \mathrm{mM}$ per day on the third day of acidosis. Phosphaturia was not as significant a feature of acidosis in these experiments as in some previously reported (1). However, it accounted in large measure for the increased excretion of titratable acid from the mean control rate of $37 \mathrm{mEq}$ per day to a peak of $68 \mathrm{mEq}$ per day. The fall in urine $\mathrm{pH}$ from a control value of 5.7 to a low of 4.7 contributed, although less significantly than phosphate excretion, to the increased excretion of acid. Since increased excretion during the first four days of acidosis was attended by no fall in plasma level, phosphate must have been derived either from skeletal or intracellular stores. The fact that in subject $\mathrm{H}$ both calcium and potassium excretion were elevated during acidosis inclines us to the view that phosphate was derived from both possible sources.

The well known excretion of fixed base at the onset of acidosis, and its subsequent replacement with ammonia are well illustrated in this experi- 
ment. During the control period, $142 \mathrm{mEq}$ of sodium and $34 \mathrm{mEq}$ of ammonia were excreted per day. On the first day of acidosis the excess chloride in the urine was largely neutralized with sodium, the rate of excretion of this latter ion rising to $310 \mathrm{mEq}$ per day, whereas that of ammonia increased only to $62 \mathrm{mEq}$ per day. By the fifth day ammonia had increased sufficiently to neutralize all excess chloride derived from the ammonium salt ingested, and the sodium balance became positive. On the first day of the recovery period the retention of dietary sodium was nearly complete, most of the urinary anions being neutralized by ammonia. A positive sodium balance was maintained for four days, during which time the alkali reserve and the salt content and volume of the several fluid compartments of the body were restored to their original condition.

During the five-day period of acidosis the net loss of sodium from the body amounted to 306 $\mathrm{mEq}$. At a mean plasma sodium concentration of $135 \mathrm{mEq}$ per liter this represents a loss of 2.3 liters of extracellular fluid. Actually body weight decreased during this interval by $2.9 \mathrm{Kgm}$. The extra weight loss probably represents intracellular fluid, for in subject $\mathrm{H}$ a significant loss of potassium was observed during the period of acidosis. It is, however, apparent that in this experiment roughly three-fourths of the weight loss can be ascribed to a reduction in volume of extracellular fluid. It is significant that in the first four days of recovery $309 \mathrm{mEq}$ of sodium were retained to balance the $306 \mathrm{mEq}$ lost during the period of acidosis. On the fifth day of recovery sodium excretion was exactly equal to the average of the five control days. Before this time body weight had been restored to normal.

A part of the fluid lost during the period of acidosis was derived from the vascular compartment, for the hematocrit, which fell steadily during the five control days, rose during the first three days of acidosis to a value appreciably above normal, to fall precipitously during the recovery period. In all some $1300 \mathrm{ml}$. of blood were drawn, relatively equally distributed over the 15 days of the experiment, so that a steady fall in hematocrit would be expected had no blood concentration resulted. No doubt because of this reduction in blood volume, glomerular filtration rate and renal plasma flow fell from their respec- tive control values of 101 and 483 cc. per min. to 86.8 and $468 \mathrm{cc}$. per $\mathrm{min}$. on the second day of acidosis, and to 92 and 402 cc. per min. on the fifth day. These changes in renal function are rather small, but had the dehydration been more severe and progressive it is probable that they would have been of greater magnitude. It must be remembered that the intake of food, fluid and salt was maintained at normal levels throughout the period of developing acidosis, a fact which must have reduced the severity of dehydration in comparison with that observed in patients suffering from diabetic ketosis or chronic nephritis, and exhibiting equivalent reduction in plasma alkali reserve. At the end of the recovery period both filtration rate and renal plasma flow had returned to levels slightly higher than those of the control period. Subject $\mathrm{H}$ who lost less weight and exhibited less dehydration suffered no decrease in filtration rate or in renal plasma flow; indeed both variables increased somewhat during acidosis. It is reasonable to infer that the dehydration which may accompany acidosis rather than the acidosis itself is the cause of the reduced renal function often observed $(8,25)$.

The results of the more extensive balance experiment performed on Subject $\mathrm{H}$ are summarized in Figures 3-5. In Figure 3 the plasma values for sodium, potassium, and calcium are presented in the left hand block, and those for chloride, bicarbonate, protein, phosphate, and sulphate are presented in the right hand block of each day's result. An undetermined moiety remains in the cation column which increases during acidosis from a control average of $6.2 \mathrm{mEq}$ per liter to 10.0 $\mathrm{mEq}$ per liter on the last day of acidosis. The undetermined moiety is no doubt in part magnesium, and if one accepts a figure of $4 \mathrm{mEq}$ per liter as a normal plasma value, the discrepancy during the control period is reduced to a satisfactorily small value. It must be remembered that the protein equivalence is calculated from total protein of serum and may well be subject to error. An increase in this error during acidosis may account for the additional slight discrepancy. On the other hand, as noted below, it may be in part due to an increase in plasma magnesium. During the control period total plasma anions average $158.2 \mathrm{mEq}$ per liter. There occurred a slight decrease during acidosis to an 


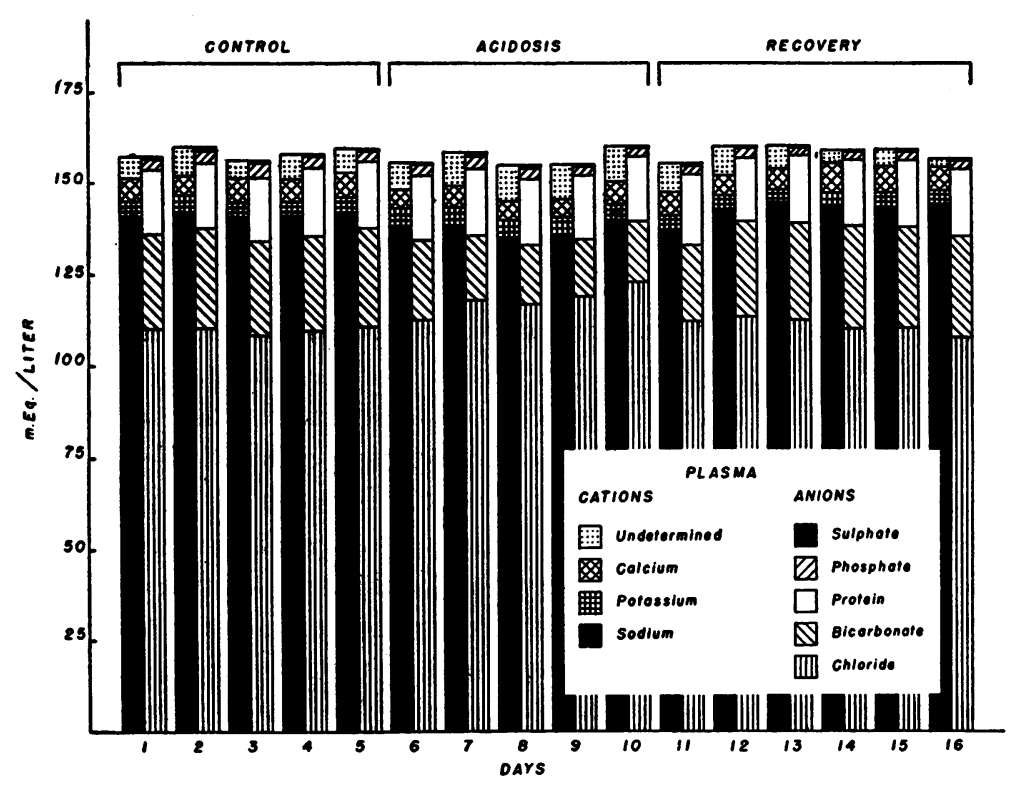

Fig. 3. Changes in the Electrolyte Pattern of the Plasma of Subject $\mathrm{H}$ Which Resulted from the Ingestion of 75 Gms. of Ammonium Chloride Over a Five-Day Period

average of 156.9 , rising again in recovery to $158.6 \mathrm{mEq}$ per liter. Plasma sodium dropped from a control average of $141.2 \mathrm{mEq}$ per liter to a low of 135.3 on the third day of acidosis, a decrease of $5.9 \mathrm{mEq}$ per liter. This decrease is slightly less than that observed in subject $P$. Chloride, in consequence of the ingestion of ammonium chloride, rose from a control average of $109.8 \mathrm{mEq}$ per liter to a peak value of 123.1 on the last day of acidosis, a rise of $13.2 \mathrm{mEq}$ per liter. Conversely bicarbonate fell during acidosis from a mean control level of $26.3 \mathrm{mEq}$ per liter to a low of $15.6 \mathrm{mEq}$ per liter on the fourth day. Again as in subject $P$, the sum of chloride and bicarbonate remained roughly constant from day to day until the second recovery day when a moderate rise occurred due to the rapid return of bicarbonate to normal. The mean control value for the sum of chloride and bicarbonate was 136.1 $\mathrm{mEq}$ per liter, a value $5.1 \mathrm{mEq}$ per liter lower than the control sodium level. This difference decreased during acidosis so that on the last day of this period it amounted only to $0.4 \mathrm{mEq}$ per liter. As may be seen from Figure 3, this change in the proportion of sodium to the sum of chloride and bicarbonate may be ascribed in part to the slight increase in plasma potassium from a mean control level of $4.26 \mathrm{mEq}$ per liter to a high of $4.95 \mathrm{mEq}$ per liter during acidosis, to the small reduction in phosphate from a control of $2.6 \mathrm{mEq}$ per liter to a low of $2.1 \mathrm{mEq}$ per liter on the last day of acidosis, and to the minor decrease in sulphate from an average of $1.1 \mathrm{mEq}$ per liter to a low of $0.8 \mathrm{mEq}$ per liter again on the last day of acidosis. The more significant change appears in the undetermined moiety and may represent some increase in plasma magnesium and possibly an error in the base binding power of the plasma proteins as noted above. Further investigation is needed to clarify this point. However, both subjects exhibited the same type of change in sodium/ anion ratio to approximately the same degree.

The plasma $\mathrm{pH}$ averaged 7.41 during the control period and fell progressively during the period of acidosis to a low of 7.29 , only to rise rapidly to a level of 7.41 on the second recovery day. An over-compensation then resulted with the $\mathrm{pH}$ increasing to 7.45 on the fourth and fifth recovery days. A similar over-compensation was observed during the recovery period with respect to sodium, calcium and bicarbonate levels.

Electrolyte excretion is graphically presented in Figure 4. Cation excretion is blocked against anion excretion for each day of the experiment. 
All values are given in milliequivalents per 24 hours. In consequence of the ingestion of ammonium chloride, total ionic excretion (sum of anions and cations) rose steadily during the period of acidosis so that on the last day of this period a total of $1248 \mathrm{mEq}$ per 24 hours were excreted as compared to a mean control value of $566 \mathrm{mEq}$. During the control period, the mean daily chloride excretion was $9 \mathrm{mEq}$ higher than the mean sodium excretion, their values being 134.5 and $125.0 \mathrm{mEq}$ per 24 hours respectively. However, with the ingestion of $15 \mathrm{gms}$. of ammonium chloride daily, chloride excretion rose progressively over the five-day period of acidosis to 470 $\mathrm{mEq}$ per 24 hours. Sodium excretion was greatest on the first day of acidosis and then fell in stepwise fashion from 293 to $50.6 \mathrm{mEq}$ per 24 hours on the second day of recovery. Potassium excretion averaged $79.8 \mathrm{mEq}$ per 24 hours during the control period, rose to a peak of 166.6 $\mathrm{mEq}$ per 24 hours on the third day of acidosis, and then fell gradually to a low of $20.9 \mathrm{mEq}$ per 24 hours on the second recovery day. It is interesting that potassium excretion had not risen appreciably by the last day of recovery even though the net deficit incurred during the period of acidosis had been almost completely regained. Calcium excretion rose to a high value of $41.4 \mathrm{mEq}$ per 24 hours on the fourth day of acidosis from a mean control value of $17.6 \mathrm{mEq}$ per 24 hours. In contrast to potassium excretion, the excretion of calcium remained above the control value during the recovery period, averaging $27.7 \mathrm{mEq}$ for the six days of this period and falling to $24.8 \mathrm{mEq}$ per 24 hours on the last day of the experiment. Magnesium excretion varied but little from a mean control level of $13.1 \mathrm{mEq}$ per 24 hours reaching a maximum of only $16.8 \mathrm{mEq}$ on the second day of acidosis and falling in the recovery period to a level only slightly below the control. With the drop in urine $\mathrm{pH}$ from a mean control level of 5.61 to an average of 4.92 during the period of acidosis, the capacity of creatinine to combine with acid became significant. Thus acid bound by creatinine rose from a mean control value of 3.8 $\mathrm{mEq}$ per 24 hours to a high of $10.1 \mathrm{mEq}$ per 24 hours on the second day of acidosis. Sulphate excretion averaged $49.4 \mathrm{mEq}$ per 24 hours during the control period, rising to 63.6 on the second day of acidosis and dropping to a low of 22.6 $\mathrm{mEq}$ per 24 hours on the first day of recovery. Phosphate excretion per 24 hours averaged several $\mathrm{mEq}$ greater than sulphate but behaved in a similar way. Organic acid excretion showed no

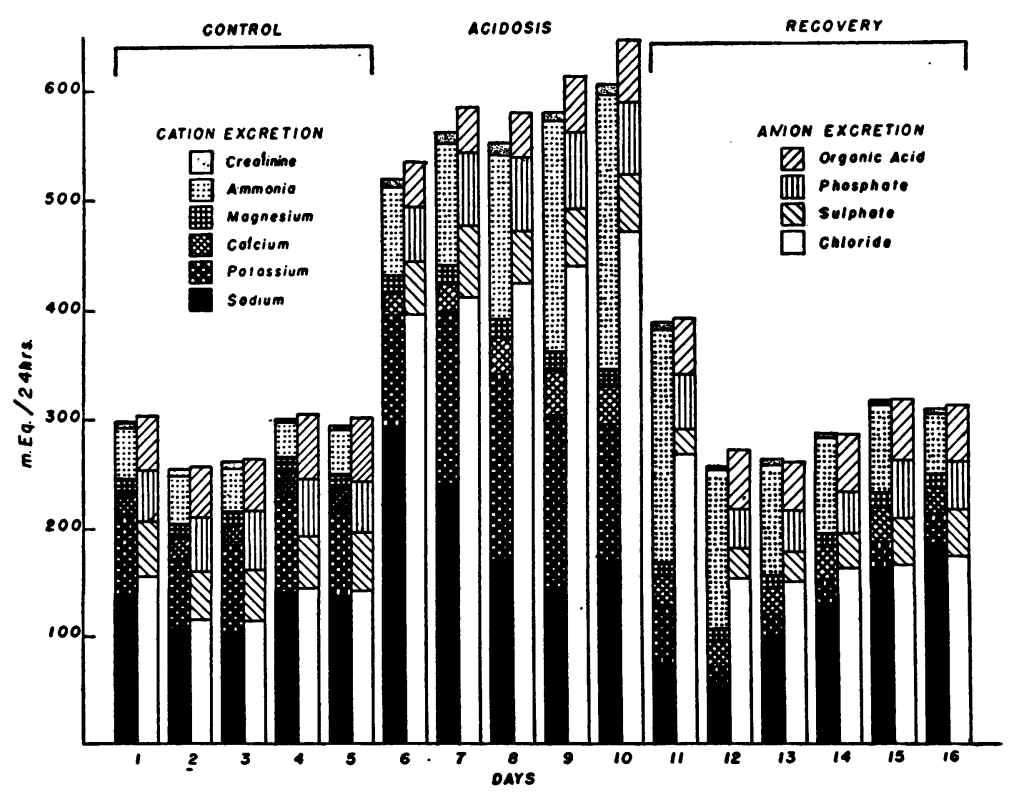

Fig. 4. Changes in the Daily Excretion of Ions of Subject $H$ Resulting from the Ingestion of 75 Gms. of Ammonium Chloride Over a Five-Day Period 
significant change during the experiment. Discrepancies between anion and cation excretion during the control and recovery periods are within limits of experimental error. During acidosis the increased discrepancy is unexplained, but might be due in part to the elimination of some undetermined organic cation, e.g., a basic amino acid such as histidine.

In the central portion of Figure 5, base conservation, as represented by the excretion of ammonia and titratable acid, is plotted upwards while fixed base loss is plotted downwards. Again, it may be clearly seen that on the first day of acidosis the excess chloride in the urine was to a large extent neutralized by sodium. On the second and succeeding days, sodium excretion was spared not only by an increase in ammonia and titratable acid excretion but also by an increase in the excretion of potassium and calcium. During the last two days of acidosis and the early days of recovery, ammonia and titratable acid excretion

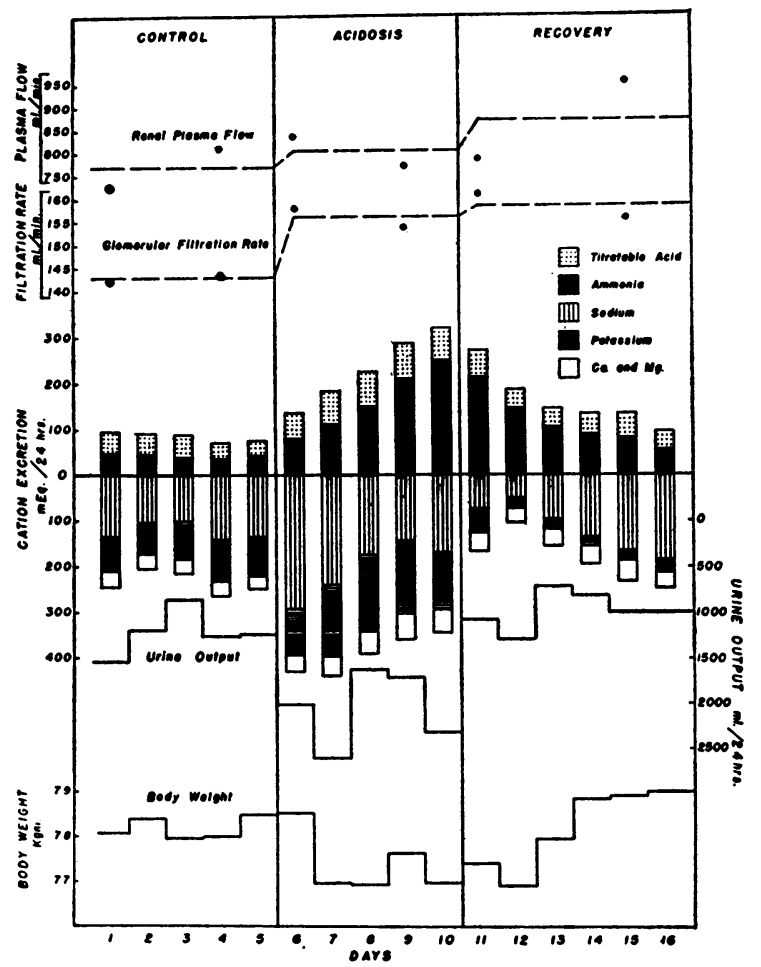

Fig. 5. Changes in the Excretion of Cations, Renal Plasma Flow, Glomerular Filtration Rate, Urine Output, and Body Weight in Subject $H$ Resulting from the Ingestion of 75 Gms. OF Ammonium Chloride Over a Five-Day Period were sufficiently great to permit a progressive and significant decrease in all elements comprising fixed base. Attention is called to the gradual return of ammonia to the control level, for in this phenomenon lies the explanation of the restoration and over-expansion of the base reserves during recovery.

Daily urine output is graphed on an inverted scale immediately below fixed base loss in Figure 5. The increase in output during the period of acidosis is in large part the result of the increased intake of water. to dilute the ammonium chloride ingested, for body weight decreased only by $1.4 \mathrm{Kgm}$. during the entire interval. Calculations of net loss of intra- and extracellular fluid during acidosis were less satisfactory in subject $\mathrm{H}$ than in subject $P$, because of less adequate dietary control and especially because of the relatively small change in body weight. Judging from the excess sodium and potassium excretion, loss of fluid was relatively equally distributed between the two compartments. Evidence of reduction in circulating blood volume either from plasma proteins or hematocrit such as that seen in subject $\mathrm{P}$ was nil. Accordingly no fall, and indeed an increase in glomerular filtration rate and renal plasma flow was observed. These increases are unexplained though they may be within limits of daily variation in this subject.

\section{Ionic reabsorption in acidosis}

It is obvious from a comparison of Figures 1 and 2, and of Figures 3, 4, and 5 that the increase in the excretion of chloride during ammonium chloride acidosis is related to the increase in plasma chloride concentration, and that the increase in excretion of sodium is the causative factor in the decrease in plasma sodium concentration and in the decline in body weight. Experiments in which glomerular filtration rate was measured permit a more exact description of the changes in renal function which underlie the altered excretion of the several ions. The significant data derived from 11 experiments performed at regular intervals on the two subjects during the control, acidosis, and recovery periods, are summarized in Tables I and II. Inasmuch as filtration rate decreased in one subject and increased in the second during acidosis, and since 


\begin{tabular}{|c|c|c|c|c|c|c|c|c|}
\hline \multirow{10}{*}{\multicolumn{2}{|c|}{ 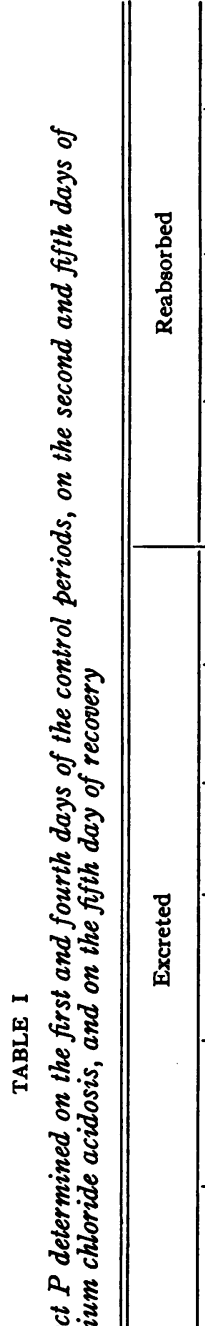 }} & 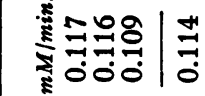 & 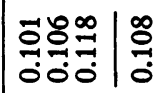 & 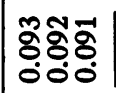 & ठ̊. & 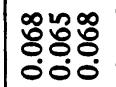 & $\mid \begin{array}{l}\hat{8} \\
0\end{array}$ & 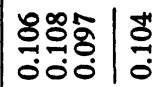 \\
\hline & & 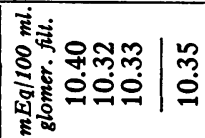 & 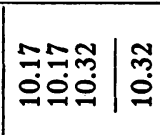 & 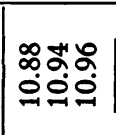 & $\mid \begin{array}{l}m \\
a \\
0\end{array}$ & 꿀워 & $\mid \stackrel{\overbrace{}}{\stackrel{n}{\Xi}}$ & 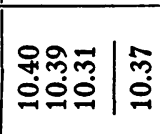 \\
\hline & & 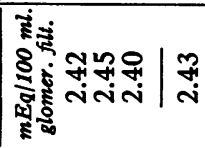 & 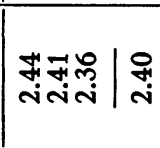 & 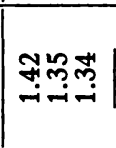 & $\mid \stackrel{s}{-i}$ & $\stackrel{\infty}{\infty} \underset{\sim}{\infty} \stackrel{\infty}{=}$ & $\mid \begin{array}{l}\infty \\
=\end{array}$ & 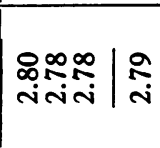 \\
\hline & & 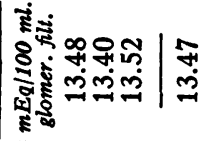 & 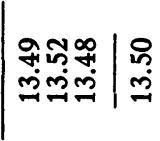 & 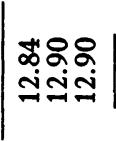 & 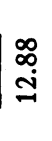 & 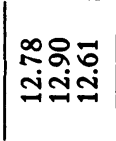 & 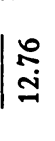 & 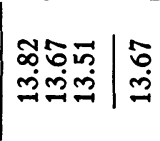 \\
\hline & & 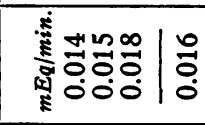 & 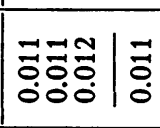 & 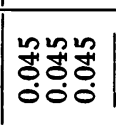 & 傗 & $\begin{array}{l}\text { 훙융융 } \\
\text { 000 }\end{array}$ & $\mid \begin{array}{l}0 \\
\text { 웅 } \\
0\end{array}$ & 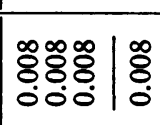 \\
\hline & & 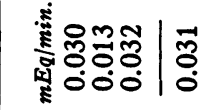 & 엉유유.ర్ర & 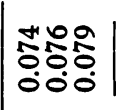 & 递 & 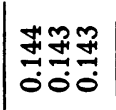 & $\mid \frac{3}{\frac{3}{0}}$ & 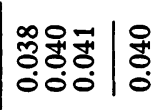 \\
\hline & & 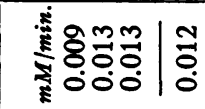 & 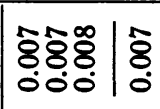 & 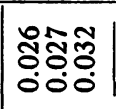 & $\mid$\begin{tabular}{c}
$\infty$ \\
\multirow{O}{0}{} \\
0
\end{tabular} & 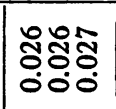 & $\mid \begin{array}{l}0 \\
0 \\
0 \\
0\end{array}$ & 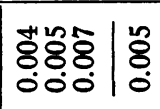 \\
\hline & & 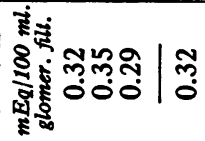 & 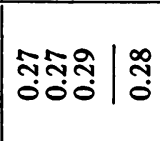 & 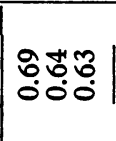 & $\mid \begin{array}{l}n \\
0 \\
0\end{array}$ & 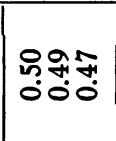 & $\mid$\begin{tabular}{l}
9 \\
\multirow{0}{0}{}
\end{tabular} & 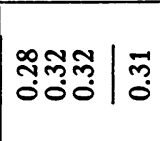 \\
\hline & & 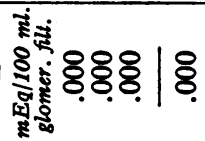 & ৪ిరిఃి & ర్రిరిర్ & 8 & రిరిరిర్ & 8 & రికిర్రి \\
\hline & & 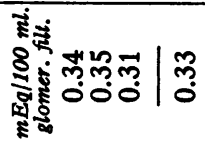 & 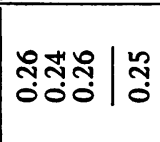 & 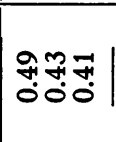 & 年 & స్లిస్సిస్తి & 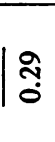 & 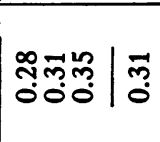 \\
\hline (5) & 客苋 & 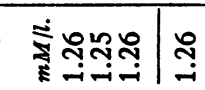 & 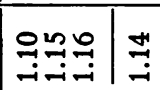 & 웕펌 & ले & 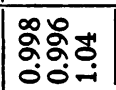 & 三人َ & 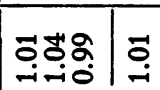 \\
\hline 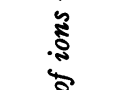 & \multirow{2}{*}{ 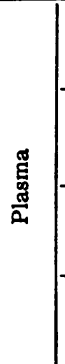 } & 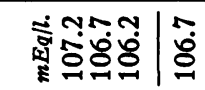 & 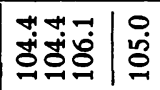 & 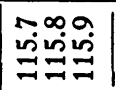 & $\stackrel{\infty}{\stackrel{\infty}{=}}$ & 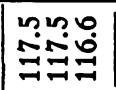 & $\mid \stackrel{\Im}{\Xi}$ & 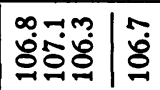 \\
\hline & & 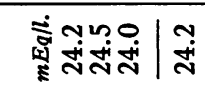 & 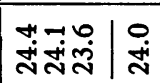 & 구료 & $\ddot{m}$ & $\stackrel{\infty}{=\infty} \underset{=}{=}=$ & $\mid \stackrel{\infty}{=}$ & 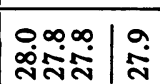 \\
\hline है & 章 & 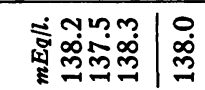 & 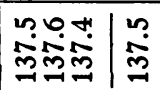 & 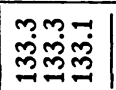 & 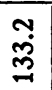 & 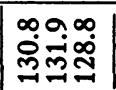 & $\mid \begin{array}{l}n \\
0 \\
0 \\
\end{array}$ & 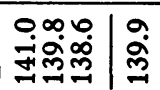 \\
\hline 离 & 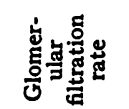 & 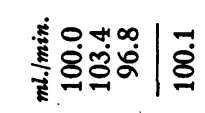 & 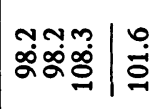 & $\mid$\begin{tabular}{l|l}
$\forall$ \\
$\infty$ \\
$\infty$
\end{tabular} & $\stackrel{\infty}{\infty}$ & 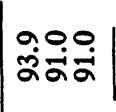 & 염 & 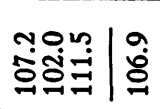 \\
\hline 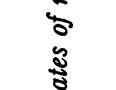 & 趈言 & 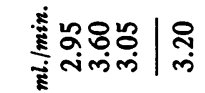 & 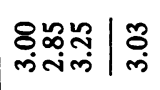 & $\mid$ & $\hat{\sigma}$ & 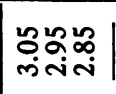 & 年 & 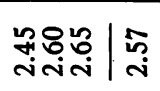 \\
\hline & & 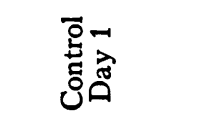 & 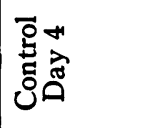 & 量 & & 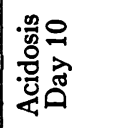 & & 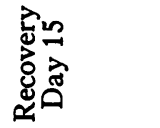 \\
\hline
\end{tabular}


previous work has shown that the quantities of sodium, bicarbonate, and chloride reabsorbed vary in proportion to glomerular filtration rate $(22,26$, $27)$, the reabsorption and excretion of these ions have been expressed in $\mathrm{mEq}$ per $100 \mathrm{ml}$. of glomerular filtrate for comparative purposes. On the other hand, in Table I, the reabsorption and excretion of phosphate have been expressed in $\mathrm{mM}$ per min., for the capacity of the kidney to reabsorb this ion is fixed, limited and independent of filtration rate (28). The rates of excretion of titratable acid and ammonia are likewise expressed in $\mathrm{mEq}$ per min., for both hydrogen ions and ammonia are eliminated by mechanisms which are basically secretory in character, hence not related to filtration rate (29).

In Table I, it may be seen that in the two control experiments at a plasma concentration of 138 $\mathrm{mEq}$ per liter, $13.5 \mathrm{mEq}$ of sodium were reabsorbed and $0.3 \mathrm{mEq}$ were excreted per $100 \mathrm{ml}$. of glomerular filtrate. In the first experiment in acidosis although the quantity of sodium delivered into the renal tubules per unit volume of filtrate was less in consequence of the drop in plasma concentration, that lesser quantity was reabsorbed less completely than under normal conditions. Excretion rose to $0.45 \mathrm{mEq}$ and reabsorption decreased to $12.9 \mathrm{mEq}$ per $100 \mathrm{ml}$. of filtrate. Indeed decreased reabsorption and increased excretion must have been the major determinants of reduced plasma concentration and of loss of sodium from the body. By the fifth day of acidosis, the urinary loss of sodium had diminished to the control level, namely $0.29 \mathrm{mEq}$ per $100 \mathrm{ml}$. of filtrate. No less than three factors contributed to diminished sodium loss: low plasma sodium concentration, i.e., reduced sodium content of the filtrate; diminished chloride load demanding excretion, i.e., intake of ammonium chloride had been cut from 15 to 10 gms. per day; and of greatest significance, increased substitution of ammonia for sodium in neutralizing urinary anions. We interpret the initial loss of sodium as the passive consequence of the increased excretion of chloride, brought about by the increased chloride load presented to the tubules. However, the reabsorption of chloride must be considered in relation to the reabsorption of bicarbonate, for previous work has shown that the mechanisms responsible for the salvage of these ions are inter- related in such a way that decreased reabsorption of one ion species is partially compensated by increased reabsorption of the other (22). Since all urines were more acid than $\mathrm{pH} 6.0$ the excretion of bicarbonate was negligible throughout the entire series of experiments. Because of reduced plasma concentration, less bicarbonate per unit volume of filtrate was presented for reabsorption in the two experiments in acidosis than in the two controls. Accordingly greater quantities of chloride were reabsorbed in acidosis than normally, e.g., 10.9 and $11.2 \mathrm{mEq}$ per $100 \mathrm{ml}$. of glomerular filtrate in acidosis, in comparison with 10.4 and $10.2 \mathrm{mEq}$ normally. Yet because of the greatly increased load of chloride, even the enhanced reabsorptive capacity was exceeded, and chloride excretion rose. Over-compensation during the recovery period is evident in the reabsorption of a greater than normal quantity of bicarbonate, the reabsorption of chloride reverting more or less to the control value.

Diminished absorption and increased excretion of sodium during acidosis with compensatory overabsorption and diminished excretion during recovery are again evident in experiments on subject $\mathrm{H}$ presented in Table II. Thus in the second control experiments $13.71 \mathrm{mEq}$ of sodium per $100 \mathrm{ml}$. of filtrate were reabsorbed and $0.12 \mathrm{mEq}$ excreted. On the first day of acidosis $13.60 \mathrm{mEq}$ were reabsorbed and $0.25 \mathrm{mEq}$ were excreted. On the first day of recovery reabsorption had increased to $13.78 \mathrm{mEq}$ and excretion had fallen to 0.036 $\mathrm{mEq}$. These days are chosen for consideration because the plasma sodium concentrations were essentially the same on all. Such changes in absorption and excretion are small, but it is upon such small changes that the negative sodium balance early in acidosis and the positive sodium balance in recovery depend. For instance, a decrease in the absorption of sodium of $0.11 \mathrm{mEq}$ per $100 \mathrm{ml}$. of filtrate would cause the loss of $250 \mathrm{mEq}$ in a day's time at the filtration rate exhibited by subject $\mathrm{H}$ on the first day of acidosis. This would be equivalent to the loss of 1.8 $\mathrm{Kgm}$. of extracellular fluid. The actual negative balance on this day was $168 \mathrm{mEq}$ of sodium rather than the $250 \mathrm{mEq}$ calculated, and the loss of weight was $1.4 \mathrm{Kgm}$. rather than $1.8 \mathrm{Kgm}$. One must infer either than the diminished absorption noted above was not maintained throughout 


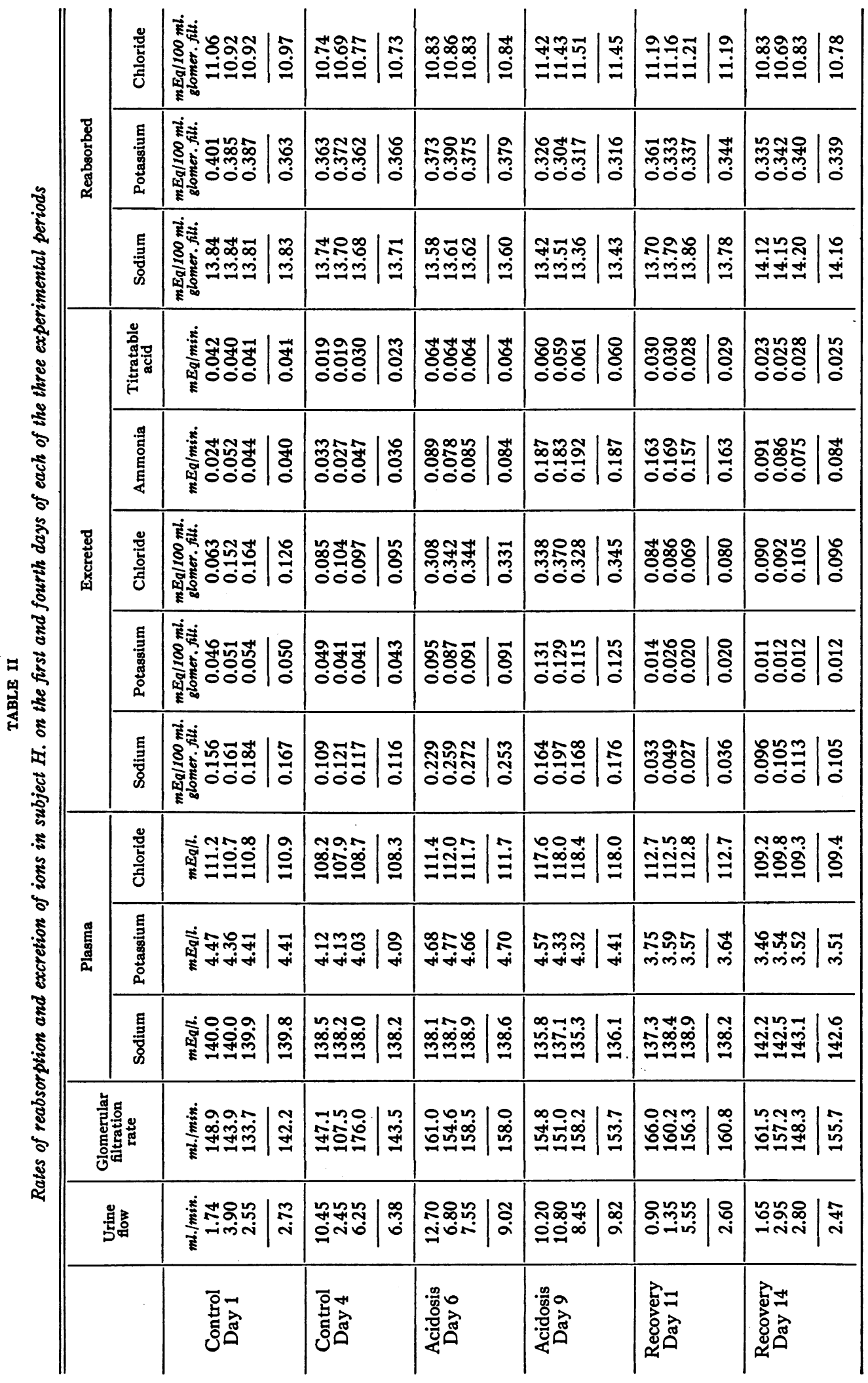


the 24 hours or that the filtration rate was lower at night (a reasonable assumption [30]). On the first day of recovery the increase in the absorption of sodium of $0.07 \mathrm{mEq}$ per $100 \mathrm{ml}$. of filtrate over the last control period would cause the retention of $161 \mathrm{mEq}$ in 24 hours and a gain of $1.2 \mathrm{Kgm}$. in weight. This quantity of sodium was not available in the diet and the actual sodium retention and weight gain were only one-third of the calculated values. A comparison of Tables I and II indicates that the greater sodium deficit, greater loss of weight and more significant fall in plasma sodium level in subject $\mathrm{P}$ as compared with subject $\mathrm{H}$ was the consequence of a greater increase in sodium excretion.

As shown in Table II potassium excretion increased sharply during acidosis, rising from a control average of $0.047 \mathrm{mEq}$ per $100 \mathrm{ml}$. of glomerular filtrate to $0.091 \mathrm{mEq}$ on the first day of acidosis and to $0.125 \mathrm{mEq}$ on the fourth day of acidosis. On this latter day at the same plasma level as on the first control day, it is evident that the absorption per $100 \mathrm{ml}$. of filtrate was significantly diminished. Despite diminished absorption and increased excretion, plasma potassium was maintained at a nearly constant level, a fact explicable only on the assumption that the excess potassium was derived from cellular stores. Loss of intracellular potassium in acidosis has been adequately demonstrated (31). During recovery, potassium excretion dropped sharply to $0.020 \mathrm{mEq}$ per $100 \mathrm{ml}$. of filtrate on the first day and to 0.012 $\mathrm{mEq}$ on the fourth day. This lower excretory rate during recovery must have been conditioned in part by the low plasma potassium level. In turn this low plasma level must have been caused by the restoration of depleted cellular reserves from the ingested and circulating moiety.

Depressed absorption of phosphate in acidosis is evident from the data of Table I. In the first experiment in acidosis 24 per cent of the filtered phosphate was excreted at a plasma concentration of $1.4 \mathrm{mEq}$ per liter; in the second, 30 per cent was excreted at a significantly lower plasma concentration. In the control periods and following recovery only 5 to 10 per cent of the filtered phosphate was excreted. These results are in line with previous findings in man, namely, that acidosis depresses the tubular reabsorption of phosphate at normal plasma levels, although it does not affect maximum tubular reabsorptive capacity at high plasma levels (32). The reduced plasma level of phosphate during recovery, like that of potassium, must have resulted from diversion of phosphate from plasma to cellular and osseous depots depleted during acidosis.

\section{Early time course of renal compensations in acido- sis}

In order to study the time course of early renal compensations in acidosis a 12 period experiment was performed in which plasma and urine samples were collected at $15 \mathrm{~min}$. intervals. During this experiment a total of 10 gms. of ammonium chloride was ingested in two doses. The significant observations are presented in Figure 6. The first two periods, performed with the subject in a state of normal acid-base balance, established control values for all variables. A $5 \mathrm{gm}$. dose of ammonium chloride was then ingested and following four additional clearance periods, another $5 \mathrm{gms}$. were taken.

Minimal changes in plasma chloride, bicarbonate and $\mathrm{pH}$ are evident within $7.5 \mathrm{~min}$. after the ingestion of the first dose of ammonium chloride.

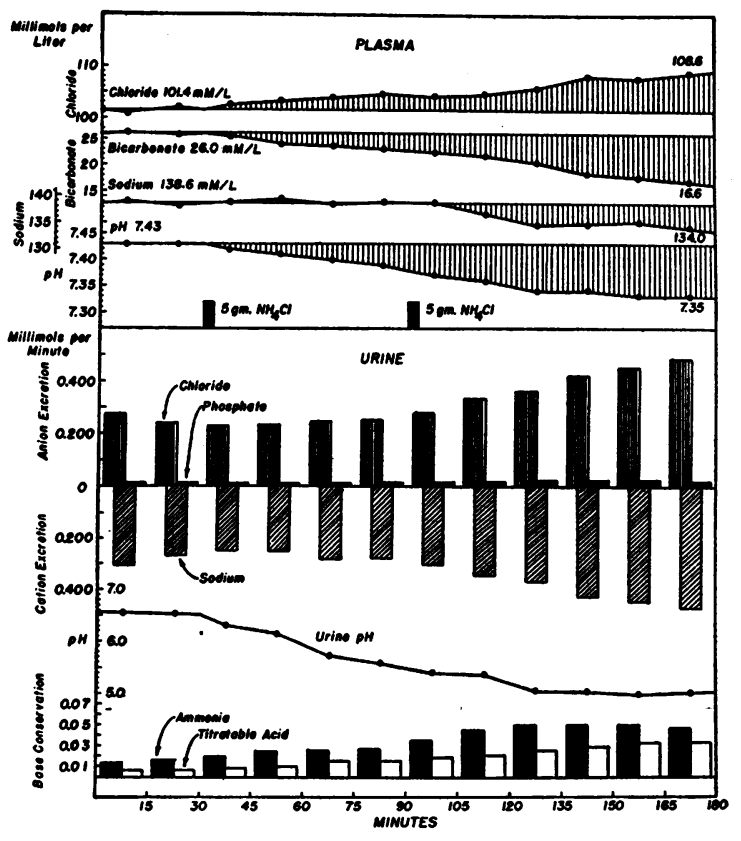

Fig. 6. Changes in Ionic Composition of the Plasma, in Rates of Excretion of Ions During the Acute Phase of a Developing Ammonium Chloride Acibosis 
These changes became progressively more significant over the succeeding $45 \mathrm{~min}$. Following the second dose, plasma chloride rose and bicarbonate, $\mathrm{pH}$ and sodium fell within the subsequent $90 \mathrm{~min}$. to levels characteristic of moderately severe acidosis. A decrease in $\mathrm{pH}$ and an increase in content of titratable acid and ammonia are evident in the urine formed within $15 \mathrm{~min}$. following the ingestion of the first dose of the acidifying salt, changes which were progressive throughout the course of the experiment. No significant changes in the excretion of phosphate, chloride and sodium were evident until the second $5 \mathrm{gms}$. of ammonium chloride were ingested, although plasma chloride rose appreciably during the interval between the two doses, a rise which was exactly counterbalanced by the fall in plasma bicarbonate. But following the second dose of the ammonium salt, chloride excretion increased, and since the excess urinary chloride was largely neutralized by sodium, the excretion of this ion increased proportionately. Only a part of the reduction in plasma sodium can be ascribed to increased excretion; the remainder must have been due to shifts of fluid and/or electrolyte between intra- and extracellular compartments.

One surprising finding in this experiment, which has been observed in others as well, was the prompt increase in the excretion of ammonia. It is usually stated that the kidney responds early to an increased acid load by excreting acid in free titratable form, and only after some delay, by excreting increased quantities of ammonia. It is evident from Figure 3 that ammonia and titratable acid excretion increased at equivalent rates and to approximately the same extent within the first $120 \mathrm{~min}$. after the ingestion of an acidifying salt. It is true that this increase in ammonia output is only a small fraction of that attained after five days, but there certainly is no true delay in its onset, merely a gradual attainment of its maximal value. If it is correct to infer that no significant increase in plasma ammonia results from the ingestion of ammonium chloride $(1,6)$, then the observed increase in the rate of ammonia excretion constitutes a prompt renal compensation to ingestion of acid. Since plasma phosphate level did not change, the increased rate of excretion of phosphate during the latter half of this experiment resulted from diminished reabsorption. Both the increase in the rate of phosphate excretion and the increase in the acidity of the urine contributed to the enhancement of titratable acid excretion.

\section{DISCUSSION}

It is apparent in ammonium chloride acidosis that the kidney maintains approximate constancy of total ionic concentration at the expense of ionic pattern and to a lesser degree at the expense of extracellular fluid volume. As bicarbonate is converted to chloride an increase in the tubular reabsorption of this latter ion species serves to restrict its loss, and thus the loss of base which accompanies it into the urine. For example, $10.3 \mathrm{mEq}$ of chloride were reabsorbed and $0.28 \mathrm{mEq}$ were excreted per $100 \mathrm{ml}$. of glomerular filtrate in the second control experiment presented in Table $I$. On the first day of acidosis increased quantities of chloride per unit volume of filtrate were delivered into the renal tubules, because of increased plasma concentration. However, an increase in reabsorption to $10.93 \mathrm{mEq}$ per $100 \mathrm{ml}$. of filtrate limited excretion to $0.65 \mathrm{mEq}$. Had no increase in chloride absorption occurred, excretion would have increased to $1.36 \mathrm{mEq}$ and the rate of sodium loss would have been tripled. It is apparent that an important renal response in ammonium chloride acidosis is the increase in tubular reabsorption of chloride, an increase which is more or less proportional to the extent of the conversion of bicarbonate to chloride. A consequence of this renal response is the maintenance of constancy of the sum of the plasma concentrations of chloride and bicarbonate despite considerable shifts in their relative proportions.

However, the conversion of a significant proportion of bicarbonate to chloride is attended by some increase in chloride excretion. Early in acidosis the excess urinary chloride is neutralized in large part by sodium derived from extracellular stores. This loss of fixed base is accompanied by the excretion of nearly equivalent quantities of water. Since the specific gravity of the urine of subject $P$ averaged 1.016 during the five days of acidosis in contrast to 1.026 during the five control days, it is probable that the polyuria and consequent loss of weight during acidosis resulted from diminished posterior pituitary activity rather than from osmotic abstraction of body water by 
concentrated urinary solutes. Indeed the probable stimulus promoting fluid elimination was the decrease in osmotic pressure of the body fluids in consequence of base loss. This is suggested by the fact that water excretion lagged somewhat behind base loss, for in both subjects plasma sodium level decreased significantly.

In subject $\mathrm{P}$ a major portion (three quarters) of the water and base sacrificed during acidosis was derived from the extracellular fluid compartment ( $c f$. calculations on p. 426). In subject $\mathrm{H}$ balances were less accurate and calculations less dependable, but fluid loss seemed more equally divided between intra- and extracellular compartments. It is significant in subject $H$ that the majority of the base lost on the first day of acidosis was sodium. However, by the third day potassium excretion had increased to a point where this ion neutralized a greater proportion of the urinary acid than did sodium. Since the plasma level of potassium did not change appreciably during acidosis, this ion must have been delivered into the blood from the tissues at essentially the same rate at which it was eliminated in the urine. The substitution of potassium for sodium in the urine permits the body to draw on the large intracellular reserves of buffer base; hence loss of interstitial fluid and reduction of circulating plasma volume are curtailed.

The changes in renal function described above are restrictive compensations, in the sense that they limit the disturbance of total ionic concentrations and volumes of both intra- and extracellular fluids. The elimination of titratable acid and especially of ammonia are corrective compensations in the sense that they permit the continued excretion of acid without further drain of base, and during recovery, rapidly restore ionic patterns, total ionic concentrations and volumes to normal. It is apparent from Figures 2 and 4 that ammonia excretion and to a lesser extent titratable acid excretion increased progressively over the five-day period of acidosis. In subject $P$, who ingested a smaller dose of ammonium chloride, the ammonia output on the fifth day was more than equivalent to the acid load, and a positive sodium balance was attained. In subject $H$, the ammonia output was sufficiently great to reduce the net loss of all components making up the fixed base of the urine, although positive balances were not attained. In the early recovery period, the continued production of ammonia at a high rate permitted the rapid restoration of base reserves. The marked positive balance of sodium in subject $P$ and of all components of fixed base except calcium in subject $\mathrm{H}$ is clearly evident in Figures 2 and 4.

Points of some possible therapeutic interest in clinical acidosis are the low plasma levels of phosphate and potassium observed during the recovery period despite the positive urinary balances. These low plasma levels undoubtedly result from the replenishment of depleted cellular reserves of potassium and phosphorus from circulating stores. Reductions in plasma levels of the magnitude observed in these experiments are inconsequential, but are in qualitative agreement with those of more significant magnitude observed following recovery from diabetic ketosis $(13,33)$.

The cause of the inverse relationship between chloride and bicarbonate reabsorption and the additional excretion of chloride and sodium in moderate and severe acidosis are interesting points for speculation. According to Walker et al. (34) the ionic pattern of the glomerular filtrate, which approximates that of the plasma, is rapidly altered during passage of the fluid through the proximal tubule. Although the sodium concentration is essentially unchanged, the chloride concentration of the residual tubular fluid rises as fluid is absorbed. One must conclude that sodium and water are reabsorbed proportionally, that chloride is absorbed infraproportionally to water, and that some other ion, most probably bicarbonate, is absorbed supraproportionally. According to Wesson et al. (30) the active absorption of sodium and its attendant anions in the proximal tubule is the origin of the osmotic force which causes the absorption of some 80 per cent of the filtered water in this segment. Possibly the tubule is relatively indifferent within narrow limits to the nature of the anion presented to it, i.e., whether chloride or bicarbonate. Thus with moderate conversion of bicarbonate to chloride diminished absorption of the former might be more or less exactly compensated by increased absorption of the latter as a semipassive partner of sodium. However, the conversion of a significant proportion of the bicarbonate to chloride might be expected to reduce total anion absorption, for from Walker's data it 
would appear that chloride absorption proceeds at a somewhat slower rate than bicarbonate absorption in the proximal segment. Reduction in total anion absorption in this segment would restrict cation (sodium) and water absorption to essentially equivalent degrees. The excess sodium over and above that normally absorbed in the distal tubule would be excreted in the urine. It is evident from Tables I and II that the magnitude of these changes is very small, a fact which renders their demonstration difficult. Nevertheless it is such small changes which underlie the negative sodium balance, diuresis and loss of weight which characterize ammonium chloride acidosis.

One is forced to the conclusion that such changes in glomerular filtration rate as occur in ammonium chloride acidosis cannot be directly responsible for changes in sodium and chloride balances. Thus qualitatively similar results in overall electrolyte balance were obtained in subjects $\mathrm{P}$ and $\mathrm{H}$, yet in the former filtration rate fell and in the latter it rose. This fact alone, were it not supported by other evidence referred to in the first part of this paper, would justify correction of reabsorption to a standard rate of filtration for comparative purposes. This does not imply that a change in filtration rate may not modify the extent of a positive or negative balance by altering the quantity of electrolyte delivered into the distal segment of the renal tubule. Indeed there is evidence that such variations in filtration rate do alter electrolyte balance significantly (30).

That the increased excretion of ammonia and titratable acid in acidosis and for the first few days of recovery are compensations which restrict the loss of fixed base and restore the base reserves, is well recognized. Undoubtedly both serve to increase the distal tubular salvage of base, for the mechanisms for ammonia and acid excretion are both located at this site $(35,36)$. The former accomplishes the exchange of $\mathrm{NH}_{4}{ }^{+}$ions for $\mathrm{B}^{+}$ions, the latter, the exchange of $\mathrm{H}^{+}$ions for $\mathrm{B}^{+}$ions (29). Thus in acidosis the delivery of additional base into the distal segment in consequence of diminished proximal tubular absorption is compensated by a greater exchange of $\mathrm{H}^{+}$ and $\mathrm{NH}_{4}{ }^{+}$ions for that base. Since as shown in Figure 6, the output of ammonia increases as rapidly as that of titratable acid following the ingestion of ammonium chloride, it is reasonable to assign these increases to a single stimulus. Basically this stimulus appears to be a reduction in the quantity of bicarbonate delivered into the distal segment of the renal tubule, or more indirectly to a reduction in plasma bicarbonate concentration, for this latter factor largely determines the former in any given individual. According to views previously expressed there is a single transfer mechanism which exchanges $\mathrm{H}^{+}$ions for $\mathrm{B}^{+}$ ions across the distal tubular epithelium (29). This mechanism is limited to some extent in transfer capacity and in the $\mathrm{H}^{+}$ion gradient which it can develop between blood and tubular urine. At normal plasma levels, that quantity of bicarbonate which reaches the distal tubule nearly saturates the exchange mechanism, i.e., bicarbonate bound base is exchange for $\mathrm{H}^{+}$ion and carbonic acid is formed. The urine formed is only moderately acid and contains relatively small quantities of titratable acid, for the carbonic acid is largely dehydrated to $\mathrm{CO}_{2}$ and water. Because of low acidity little ammonia diffuses into the urine. At reduced plasma levels such as those observed in acidosis, little bicarbonate reaches the distal tubule. Fixed acid buffers are converted to titratable acid to the limit of the capacity of the kidney to establish an high hydrogen ion gradient. Because of high acidity of the urine ammonia diffuses from its site of formation in the distal tubular cells into the tubular lumen. This latter process, by reducing the hydrogen ion gradient between blood and urine permits the continued exchange of $\mathrm{H}^{+}$for $\mathrm{B}^{+}$ions. In essence, in the absence of sufficient bicarbonate or fixed buffer in the tubular urine to provide the requisite base to saturate the exchange mechanism, that base is derived from salts of strong acid by the substitution of ammonia as the neutralizing ion.

It is obvious that some factor other than plasma bicarbonate must condition the rate of excretion of ammonia, for ammonia output increased progressively during the five-day period of acidosis, although plasma bicarbonate had reached its lowest point by the third day. The nature and mode of operation of this factor is unknown at present.

\section{SUMMARY}

Ammonium chloride was given in divided dosage to two healthy adult subjects in order (a) 
to relate the rates of excretion of the several ions to their respective plasma concentrations; $(b)$ to determine the nature and extent of the changes in glomerular filtration, renal plasma flow, and ionic reabsorption which underlie altered excretory functions in metabolic acidosis; and (c) to study the time relations of the renal compensations to acidosis.

Following the ingestion of ammonium chloride, plasma bicarbonate fell in exact proportion to the increase in plasma chloride, so that the sum of these anions remained unchanged. During the recovery phase, plasma bicarbonate rose more rapidly than chloride fell, resulting in an increase in the sum of these anions. Although the ability of the renal tubules to reabsorb chloride increased as the load of bicarbonate presented in the filtrate was reduced, the increase was not sufficient to prevent loss of chloride in the urine. Early in acidosis the excess urinary chloride was neutralized for the most part by sodium derived from body buffers. Loss of sodium resulted in a moderate reduction of plasma sodium concentration which was limited by the excretion of nearly equivalent quantities of water.

Three different mechanisms were responsible for the restriction of sodium loss and the restoration of body buffer reserves: ( $a$ ) following the ingestion of an acidifying salt, the increase in chloride reabsorption per $100 \mathrm{ml}$. of glomerular filtrate significantly diminished the loss of fixed base; (b) the increased excretion of potassium and calcium on the second and third days of acidosis permitted a decrease in sodium excretion although total fixed base loss increased; $(c)$ ammonia and titratable acid production increased progressively during acidosis permitting the continued excretion of acid with a reduction in the loss of fixed base. A lag in the return of ammonia to normal during recovery resulted in an over-compensatory increase in plasma sodium and bicarbonate.

Despite the fact that glomerular filtration rate and renal plasma flow varied in opposite directions in the two subjects during ammonium chloride acidosis, sodium, potassium and chloride balances followed a similar pattern. Chloride reabsorption increased and sodium and potassium reabsorption decreased per $100 \mathrm{ml}$. of glomerular filtrate in both subjects. Despite the diminished absorption and increased excretion, plasma potas- sium was maintained at a nearly constant level, thus indicating the release of intracellular stores of this ion. Phosphate likewise was released from either cellular or osseous stores.

Alterations in electrolyte pattern and balance during acidosis were also studied in acute experiments. It was observed that ammonia and titratable acid excretion increased at equivalent rates and to approximately the same extent within the first two hours after the ingestion of an acidifying salt. However, only a small fraction of the maximal rate of ammonia formation is attained within this time interval. The basis for the delay in attainment of the maximal rate of ammonia excretion early in acidosis and the persistence of a high rate of excretion during recovery is unexplained at present.

\section{BIBLIOGRAPHY}

1. Peters, J. P., and Van Slyke, D.D., Quantitative Clinical Chemistry. Vol. I, Interpretations, Vol. II, Methods, Williams and Wilkins Co., Baltimore, 1932.

2. Henderson, L. J., and Palmer, W. W., On the intensity of urinary acidity in normal and pathological conditions. J. Biol. Chem., 1913, 13, 393.

3. Pitts, R. F., Lotspeich, W. D., Schiess, W. A., and Ayer, J. L., The renal regulation of acid-base balance in man. I. The nature of the mechanism for acidifying the urine. J. Clin. Invest., 1948, 27, 48.

4. Gamble, J. L., Blackfan, K. D., and Hamilton, B., A study of the diuretic action of acid producing salts. J. Clin. Invest., 1925, 1, 359.

5. Gamble, J. L., Ross, G. S., and Tisdall, F. F., Studies of tetany. I. The effect of calcium chloride ingestion on the acid-base metabolism of infants. Am. J. Dis. Child., 1923, 25, 455.

6. Folling, A., On the mechanism of ammonium chloride acidosis. Acta med. Scandinav., 1929, 71, 221.

7. Salter, W. T., Farquharson, R. F., and Tibbetts, D. M., Studies of calcium and phosphorus metabolism. XIX. The effect of diet on urinary acid and ammonia excretion in man. J. Lab. \& Clin. Med., 1933, 18, 669.

8. McCance, R. A., and Lawrence, R. D., The secretion of urine in diabetic coma. Quart. J. Med., 1935, 4, 53.

9. Linder, G., The effect of mineral acid on acid-base regulation in health and in nephritis. Quart. J. Med., 1927, 20, 285.

10. Peters, J. P., Bulger, H. A., Eisenman, A. J., and Lee, C., Total acid-base equilibrium of plasma in health and disease. VI. Studies of diabetes. J. Clin. Invest., 1925, 2, 167. 
11. Gamble, J. L., Ross, S. G., and Tisdall, F. F., The metabolism of fixed base during fasting. J. Biol. Chem., 1923, 57, 633.

12. Stillman, E., Van Slyke, D. D., Cullen, G. E., and Fitz, R., Studies on acidosis. VI. The blood, urine and alveolar air in diabetic acidosis. $\mathrm{J}$. Biol. Chem., 1917, 30, 405.

13. Atchley, D. W., Loeb, R. F., Richards, D. W., Jr., Benedict, E. M., and Driscoll, M. E., On diabetic acidosis. A detailed study of electrolyte balances following the withdrawal and reestablishment of insulin therapy. J. Clin. Invest., 1933, 12, 297.

14. Odin, M., Studien über die Säureproduktion bei Diabetes Mellitus. Acta med. Scandinav., Suppl. 18, 1927.

15. Odin, M., Die Ursache des raschen Eintretens vom Koma auf plötzliches Abbrechen der Insulinzufuhr bei insulinbehandelten diabetesfällen. Acta med. Scandinav., 1928, 69, 254.

16. Henderson, L. J., and Palmer, W. W., On the several factors of acid excretion in nephritis. J. Biol. Chem., 1915, 21, 37.

17. Van Slyke, D. D., Linder, G. C., Hiller, A., Leiter, L., and McIntosh, J. F., The excretion of ammonia and titratable acid in nephritis. J. Clin. Invest., 1926, 2, 255.

18. Bulger, H. A., Peters, J. P., Eisenman, A. J., and Lee, C., Total acid-base equilibrium of plasma in health and disease. VII. Factors causing acidosis in chronic nephritis. A preliminary report. J. Clin. Invest., 1926, 2, 213.

19. Gamble, J. L., Chemical anatomy, physiology and pathology of extracellular fluid. A lecture syllabus. Dept. Pediatrics, Harvard Medical School, 1941.

20. Butler, A. M., and Tuthill, E., An application of the uranyl zinc acetate method for determination of sodium in biological material. J. Biol. Chem., 1931, 93, 171.

21. Phillips, R. A., Van Slyke, D. D., Dole, V. P., Emerson, K.; Jr., Hamilton, P. B., and Archibald, R. M., Copper sulfate method for measuring specific gravities of whole blood and plasma. Publ. U. S. Navy Research Unit, Hospital of Rockefeller Institute.

22. Pitts, R. F., and Lotspeich, W. D., Bicarbonate and the renal regulation of acid-base balance. Am. J. Physiol., 1946, 147, 138.
23. Berger, E. Y., Farber, S. J., and Earle, D. P., Jr., Renal excretion of mannitol. Proc. Soc. Exper. Biol. \& Med., 1947, 66, 62.

24. Gray, J. S., Reply to " Krueger's criticism of multiple factor theory." Science, 1947, 105, 466.

25. McCance, R. A., and Widdowson, E. M., The secretion of urine in man during experimental salt deficiency. J. Physiol., 1937, 91, 222.

26. Mokotoff, R., Ross, G., and Leiter, L., Renal plasma flow and sodium reabsorption and excretion in congestive heart failure. J. Clin. Invest., 1948, $27,1$.

27. Lotspeich, W. D., Swan, R. C., and Pitts, R. F., The renal tubular reabsorption of chloride. Am. J. Physiol., 1947, 148, 445.

28. Ayer, J. L., Schiess, W. A., and Pitts, R. F., Independence of phosphate reabsorption and glomerular filtration in the dog. Am. J. Physiol., 1947, 151, 168.

29. Pitts, R. F., Renal excretion of acid. Federation Proc., 1948, 7; 418.

30. Wesson, L. G., Jr., Anslow, W. P., Jr., and Smith, H. W., The excretion of strong electrolytes. Bull. N. Y. Acad. Med., 1948, 24, 586.

31. Elkinton, J. R., Winkler, A. W., and Danowski, T. S., Transfers of cell sodium and potassium in experimental and clinical conditions. J. Clin. Invest., 1948, $27,74$.

32. Schiess, W. A., Ayer, J. L., Lotspeich, W. D., and Pitts, R. F., The renal regulation of acid-base balance in man. II. Factors affecting the excretion of titratable acid by the normal human subject. J. Clin. Invest., 1948, 27, 57.

33. Guest, G. M., Organic phosphates of the blood and mineral metabolism in diabetic acidosis. Am. J. Dis. Child., 1942, 64, 401.

34. Walker, A. M., Bott, P. A., Oliver, J., and MacDowell, M. C., The collection and analysis of fluid from single nephrons of the mammalian kidney. Am. J. Physiol., 1941, 134, 580.

35. Montgomery, H., and Pierce, J. A., The site of acidification of the urine within the renal tubule in amphibia. Am. J. Physiol., 1937, 118, 144.

36. Walker, A. M., Ammonia formation in the amphibian kidney. Am. J. Physiol., 1940, 131, 187. 